\title{
ГРУППОВОЙ СОСТАВ ЛИПИДОВ ИЗ ПОВЕРХНОСТНОГО СЛОЯ ДОННЫХ ОСАДКОВ БАЛТИИСКОГО МОРЯ
}

\author{
(Представил М. Губергриц)
}

При исследовании загрязнения водоемов наибольший интерес представляет поверхностной слой донных отложений как источник интегративной информации о количественном и качественном характере загрязнения за недавний период времени, элиминирующий при этом незначительные флуктуации концентраций компонентов. В то же время поверхностный слой осадков сам является загрязнителем, так как токсические вещества, мигрируя из глубины на поверхность, испытывают в придонной воде вторичное растворение.

\section{Методика анализа}

В данной работе исследован групповой состав липидов, выделенных из поверхностного слоя $(0-2,5$ см) донных отложений Балтийского моря. Всего проанализировано девять проб - шесть со станций «векового разреза» в Финском заливе, одна со станции LL-3A мониторинга Хельсинкской конвенции, одна со станции, расположенной к северу от о-ва Хийумаа, и одна со станции Таллинского залива. Пробы отбирали с помощью сконструированной в Институте химии АН ЭССР донной трубки из нержавеющей стали и хранили до проведения анализов при температуре $-20^{\circ}$ в стеклянной посуде. Для извлечения из проб органических соединений к 50 г морского осадка прибавляли 30 мл ацетона, перемешивали в течение 10 мин и центрифугировали. Ацетон декантировали и процедуру повторяли. Затем дважды экстрагировали $H$-гексаном тем же способом. Экстракты соединяли и добавляли 100 мл $2 \%$-ного раствора $\mathrm{Na}_{2} \mathrm{SO}_{4}$. Верхний слой отделяли, растворитель выпаривали.

Экстракты разделяли на группы методом тонкослойной хроматографии. Сухой остаток растворяли в ацетоне и наносили на пластинку с силикагелем марки Л, размеры зерен 5-40 мкм (фирмы «Chemapol», Чехословакия). После улетучивания ацетона пластинку элюировали $н$-гексаном. В качестве эталонных веществ использовали нафталин и тетралин. Проявителем служила смесь формалина $\mathrm{c}_{2} \mathrm{SO}_{4}$.

Групповой состав экстракта пробы донного осадка с 4-й станции по данным метода тонкослойной хроматографии на силикагеле: I - гетеросоединения, II - полициклические ароматические углеводороды, III - моноциклические ароматические углеводороды, IV - алканы и цикланы; 1 - нафталин, 2 - тетралин.
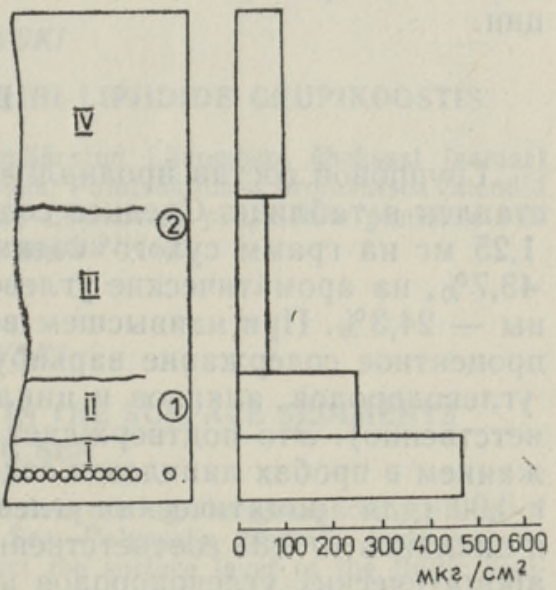


\begin{tabular}{|c|c|c|c|c|c|c|c|c|c|}
\hline \multirow[b]{2}{*}{ 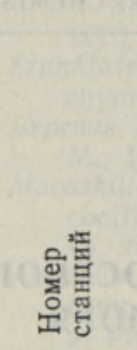 } & \multirow[b]{2}{*}{ 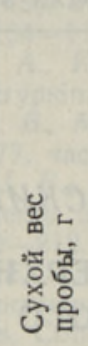 } & \multirow{2}{*}{ 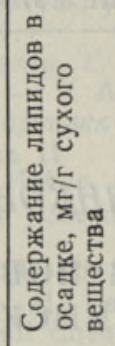 } & \multicolumn{4}{|c|}{$\begin{array}{c}\text { Содержание, мкг/r сухого } \\
\text { вещества }\end{array}$} & \multicolumn{3}{|c|}{$\underset{\%}{\Gamma \text { рупповой состав, }}$} \\
\hline & & & & 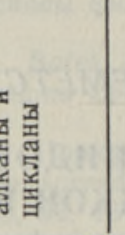 & 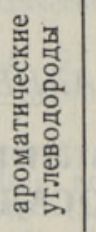 & 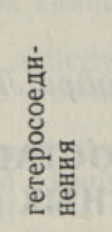 & 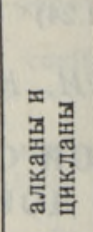 & 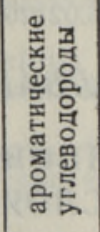 & 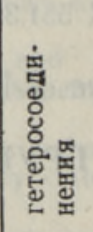 \\
\hline 1 & 47,0 & 0,11 & 34,3 & $75,4^{*}$ & 11,9 & 63,8 & 31,2 & 10,8 & 58,0 \\
\hline 2 & 13,8 & $\begin{array}{ll}3,28 & 1\end{array}$ & 1512,1 & $331,2^{*}$ & 393,6 & 1374,3 & 46,1 & 12,0 & 41,9 \\
\hline 3 & 20,6 & 2,03 & 314,7 & & 891,2 & 824,2 & 15,5 & 43,9 & 40,6 \\
\hline 4 & 20,8 & 2,23 & 243,1 & $105,4^{*}$ & 952,2 & 1034,7 & 10,9 & 42,7 & 46,4 \\
\hline 5 & 39,9 & 0,89 & 267,9 & & 327,5 & 294,6 & 30,1 & 36,8 & 33,1 \\
\hline 6 & 20,8 & 1,11 & 218,7 & $107,6^{*}$ & 497,3 & 394,1 & 19,7 & 44,8 & 35,5 \\
\hline 7 & 25,7 & 0,42 & 81,5 & $11,0^{*}$ & 85,7 & 252,8 & 19,4 & 20,4 & 60,2 \\
\hline 8 & 15,2 & 0,33 & 73,3 & $27,2^{*}$ & 147,8 & 108,9 & 22,2 & 44,8 & 33,0 \\
\hline 9 & 26,3 & 0,89 & 211,8 & & 281,2 & 396,9 & 23,8 & 31,6 & 44,6 \\
\hline \multicolumn{2}{|l|}{$\begin{array}{l}\text { Среднее } \\
\text { значение }\end{array}$} & 1,25 & 328,2 & & 398,7 & 527,1 & 24,3 & 32,0 & 43,7 \\
\hline \multicolumn{2}{|c|}{$\begin{array}{l}\text { Стандартное } \\
\text { отклонение }\end{array}$} & 1,05 & 453,1 & & 333,2 & 449,6 & 10,4 & 14,1 & 9,9 \\
\hline \multicolumn{2}{|c|}{ Вариация, \% } & 84,0 & 138,1 & & 83,6 & 85,3 & 42,8 & 44,1 & 22,6 \\
\hline
\end{tabular}

* Данные ИК-спектрофотометрин.

По $R_{f}$ нафталина и тетралина органические соединения разделяли на фракции и вымывали из силикагеля ацетоном. После выпаривания растворителя фракции взвешивали. Потери составляли до $26 \%$. На рисунке в качестве примера приведены результаты разделения пробы с 4-й станции.

\section{Результаты}

Групповой состав проанализированных проб донных осадков представлен в таблице. Среднее содержание липидов в пробах составляет 1,25 мг на грамм сухого седимента: на гетеросоединения приходится $43,7 \%$, на ароматические углеводороды $-32,0 \%$, на алканы и цнкланы $-24,3 \%$. При наивысшем весовом содержании гетеросоединений их процентное содержание варьирует намного меньше, чем ароматических углеводородов, алканов и цикланов (вариации 22,6, 44,1 и 42,8\% соответственно). Это подтверждает и наилучшая корреляция между содержанием в пробах липидов и содержанием там группы гетеросоединений: $r 0,99$ (для ароматических углеводородов $r$ составляет 0,68 , для алканов и цикланов - 0,83 соответственно). Больше половины (в среднем $56,6 \%$ ) ароматических углеводородов представлено полициклическими соедине- 
ниями с конденсированными ядрами, характерными для продуктов термической переработки горючих ископаемых.

Содержание липидов в Финском заливе увеличивается с запада на восток. Основная часть седиментационного материала поступает в восточную часть залива. Из $1,2 \cdot 10^{6}$ т взвешенного материала, ежегодно аккумулирующегося в Финском заливе, примерно треть поставляется Невой. Из растворенного стока Невой поставляется более половины [']. Наивысшей концентрацией как липидов, так и алканов и цикланов характеризуется проба с самой восточной станции «векового разреза», что свидетельствует о локализации загрязнений в этом районе.

Концентрацию нефтепродуктов в пробах определяли весовым методом и, выборочно, ИК-спектрофотометрией, чтобы сравнить результаты (таблица). И хотя весовой метод дал завышенные результаты по сравнению с ИК-спектрофотометрией, коэффициент корреляции между данными обонх методов был довольно высок $(r 0,95)$. Выбор в пользу весового метода мы посчитали оправданным, поскольку для других возможных методов или отсутствует общая основа количественного анализа (напр., проблемы стандарта при спектрофотометрических определениях), или же анализ является технически сложным.

\section{Выводы}

1. Содержание в поверхностном слое донных осадков Финского залива как липидов, так и неполярных углеводородов увеличивается с запада на восток.

2. В групповом составе липидов значительную роль играют ароматические соединения, около половины из которых представлены полициклическими ароматическими углеводородами. Этот факт свидетельствует о загрязнении поверхностного слоя донных осадков Балтийского моря продуктами термической переработки горючих ископаемых.

\section{Л И ТЕРА Т У Р А}

1. Геология Балтийского моря. Под ред. В. Гуделиса и Е. Емельянова. Вильнюс, 1976, 310.

Институт термофизики и электрофизики Академии наук Эстонской ССР

Поступила в редакцию 25/XI 1986

\section{Anne TALVARI, Kadri LAANEMETS, H. JANKOVSKI}

\section{LAANEMERE POHJASETETE PINDMISE KIHI LIPIIDIDE GRUPIKOOSTIS}

Kasutades ōhukese kihi kromatograafiat on määratud Läänemere üheksast jaamast võetud pōhjasetete pindmise kihi lipiidide grupikoostis. Polütsüklilised aromaatsed ühendid moodustavad $10-15 \%$ lipiididest. See fakt kinnitab Läänemere põhjasetete pindmise kihi saastumist kütuste või nende termilise töötlemise produktidega.

\section{Anne TALVARI, Kadri LAANEMETS, H. JANKOVSKI}

\section{THE GROUP COMPOSITION OF LIPIDS IN THE SURFACE SEDIMENTS OF THE BALTIC SEA}

Thin layer chromatography has been used for determining the group composition of lipids from the surface sediments in the Baltic Sea. Polycyclic aromatic hydrocarbons form $10-15 \%$ of the lipids. The fact indicates that the surface layer of the Baltic sediments is contaminated with fuels or their thermal decomposition products. 